\title{
Analysis of Teaching Cases from Offline to Online Mode
}

\author{
Zhanguo Li*, Donghong Shan \\ School of Computer, Pingdingshan University, Pingdingshan City, China
}

Email address:

lizhanguo01@sohu.com (Zhanguo Li)

${ }^{*}$ Corresponding author

\section{To cite this article:}

Zhanguo Li, Donghong Shan. Analysis of Teaching Cases from Offline to Online Mode. Teacher Education and Curriculum Studies. Vol. 5, No. 4, 2020, pp. 156-160. doi: 10.11648/j.tecs.20200504.12

Received: October 16, 2020; Accepted: October 30, 2020; Published: November 16, 2020

\begin{abstract}
With the development of Internet technology, computer network teaching has also been popularized, and teaching methods have also evolved from traditional classroom teaching to Internet teaching. Therefore, traditional teaching models, online and offline teaching models, and online teaching models have emerged. Different teaching modes have different teaching effects due to different teaching environments and methods. This article discusses the teaching process and results of the three teaching modes through examples, and analyzes and compares the teaching effects under different teaching modes. The traditional teaching mode has the characteristics of strong classroom control ability and good teaching effect. However, the traditional teaching model may have the problem of being teacher-centered, students' lack of initiative in learning, and insufficient use of network resources. The online and offline teaching hybrid model can make full use of online and offline teaching resources, but if the management of the student's online teaching process is not in place, the problem of poor teaching effect will easily occur. In the actual implementation process, we found some problems: because online courses are mainly self-study by students, online learning cannot be managed uniformly, and there may be a phenomenon of brushing online courses. This teaching mode can save teaching classroom resources and teachers' teaching workload. The online teaching mode can realize remote online teaching and management, and use network teaching resources for remote decentralized teaching when centralized teaching is impossible. In the teaching process, various teaching modes adapt to different teaching environments, and different teaching modes should be used for teaching according to different teaching environments.
\end{abstract}

Keywords: Traditional Teaching Mode, Online and Offline Teaching Mode, Network Online Teaching Mode, Teaching Case

\section{Introduction}

The traditional teaching model is based on classrooms and laboratories as the teaching environment, with teachers speaking and students as the main teaching activities. This method is convenient for teaching management, but it uses less modern teaching environment and methods. In teaching activities, there may be teacher-centered, students' passive learning and poor teaching effects. For this reason, the reference $[1,2]$ proposes a fusion model of traditional teaching mode and other teaching modes. Reference [3-5] discusses the solution to the problem of teacher-centered teaching in traditional teaching and low student enthusiasm in learning.

O2O (Online to Offline) hybrid teaching is an "online" + "offline" teaching that combines the advantages of Internet online teaching and traditional classroom and laboratory teaching. According to different majors and courses, different teachers have proposed different mixed teaching models. For example, reference literature [6-8] discussed and practiced online and offline mixed teaching models; reference [9] proposed a mixed teaching model based on SPOC. Through the organic combination of the two forms of teaching organization, learners' learning can be guided from shallow to deep to deep learning; Reference [10] compares three common mixed teaching modes under the background of MOOC; Reference [11] is about $\mathrm{O} 2 \mathrm{O}$ The training mode of OBE engineering talents under the environment is studied.

With the development of Internet and mobile Internet technologies, there are more and more teaching modes based on OL (OnLine). Reference [12] discusses the curriculum resources and teaching mode design for online teaching; Reference [13] analyzes the practice and effects of online teaching; Reference [14] discusses the curriculum teaching mode under the background of "Internet +", reference [15] 
explores the mobile teaching mode based on the Chaoxing Learning Communication platform; Reference [16] studies the teaching methods under the "cloud teaching" mode of colleges and universities.

Regarding the teaching effects of these teaching modes, this thesis compares, analyzes and evaluates the teaching process and teaching effects of different teaching modes in the course of "University Computer Fundamentals" in our school for three semesters.

\section{Traditional Teaching Mode}

The traditional teaching mode is to give theory lessons in the classroom and experiment lessons in the laboratory. The theory class is mainly explained by the teacher, and it can interact with the students during the teaching process, or use the flipped classroom method for teaching. The traditional teaching mode is 2 hours of classroom theory teaching +2 hours of laboratory experiment per week, which is characterized by taking up a lot of teacher hours. In terms of teaching effects, the teachers in the theoretical teaching part reported that students in classroom teaching have the phenomenon of watching mobile phones and sleeping, and most students in experimental teaching can complete experiments and submit experimental reports. Table 1 shows the assessment results of the traditional teaching model.

Table 1. Statistics of traditional teaching modes (first half of 2019).

\begin{tabular}{llllll}
\hline Class & Final exam & Test & Attendance & Comprehensive & Failing \\
\hline ClassA & 71.9 & 87.4 & 99.7 & 77.8 & 0 \\
ClassB & 80.6 & 89.3 & 100 & 84.6 & 0 \\
ClassC & 74.9 & 88.1 & 99.7 & 80.0 & 0 \\
ClassD & 78.9 & 83.3 & 100 & 82.1 & 1 \\
average & 76.6 & 87.0 & 99.8 & 81.1 & \\
\hline
\end{tabular}

(Data source: Statistics of Li Zhanguo's teaching class)

The final result is the result of the final examination. The examination method is an online examination. The examination questions are objective questions. There are 80 multiple-choice questions and 20 judgment questions. The content of the exam is $30 \%$ in theory and $70 \%$ in practice. Using random test papers, there are about 1000 questions in the question bank. Judging from the test results, the class average score is the highest 80.6 points, the lowest 71.9 points, the total average score is 76.6 points, the score is basically a good level. However, the average grade difference in the final exam is 8.7 points, and the difference in class is still quite large. This has a lot to do with class management and class style of study.

Attendance is an assessment of the sign-in status of theoretical and experimental classes. Attendance in most classes is very good, basically reaching $100 \%$. This is also the strength of traditional classrooms, which shows that traditional teaching models are relatively strong in classroom management.

The experimental results are the evaluation of the experimental results. The experimental results are the results of the experimental report. After the students do the experiment in the laboratory, they upload the experimental report platform, and then the teacher will give five grades according to the experimental correction standard, and finally form a comprehensive score for all experiments. From the assessment results, the average score of each class is 87, which is relatively high in terms of teaching effect.

The comprehensive score is a combination of the usual scores and the final exam. The usual scores account for $30 \%$, and the final scores account for $70 \%$. The total average score is 81.1 points. This score is above good, and the number of failing is relatively low. In short, the traditional teaching model can meet the teaching requirements and achieve the teaching purpose.

\section{O2O Teaching Mode}

The $\mathrm{O} 2 \mathrm{O}$ (Online to Offline) teaching model is to make full use of Internet technology to promote the organic integration of traditional learning methods and online learning, break the time and space limitations of traditional classroom teaching models, and provide students with online (online teaching) with the help of the online curriculum resource center teaching platform And offline (classroom and laboratory teaching) learning spaces, not only give full play to the leading role of teachers in guiding, enlightening, and monitoring the teaching process, but also fully tap the initiative, enthusiasm and creativity of students as the main body of learning, and realize student independence under the guidance of teachers The learning mode enables students to use a high-level learning environment at an appropriate time to achieve the best learning results.

The $\mathrm{O} 2 \mathrm{O}$ teaching mode is 2 hours of network self-study + 2 hours of laboratory experiment per week. Theoretical teaching is mainly based on students' self-study on the network platform, supplemented by online tutoring by teachers, and finally assessed by online learning time. The e-learning platform adopts the school's customized learning communication platform, under which the teaching content is displayed in units of courses, and natural classes are used as management units. It has the functions of learning statistics, sign-in, answering questions and exams. Experimental teaching is basically the same as the traditional method, so I won't repeat it here.

Under the $\mathrm{O} 2 \mathrm{O}$ teaching mode, all online theoretical and experimental operation course contents are published on the Xuexitong platform, and students are required to conduct online learning as required. The method of centralized experiment in the laboratory is used offline. During the experiment, the teacher provides timely explanation and guidance. Finally, the experiment report is submitted on the network platform, and the teacher corrects the experiment report to form the experimental result.

The ultimate goal of developing $\mathrm{O} 2 \mathrm{O}$ hybrid teaching is not to use online teaching platforms to replace traditional classroom and laboratory teaching, but to effectively improve the learning effects of most students in an online and offline 
environment. However, in the actual implementation process, we found some problems. Since the online courses are mainly self-study by students, the teachers did not conduct unified classes and could not perform unified sign-in. Some students had the phenomenon of online courses being brushed. This teaching method can save theoretical teaching resources and save teachers' workload. Because classroom teaching is no longer carried out, a lot of classrooms are saved. This school, which is tight on classrooms, has indeed solved the problem of insufficient classrooms. Since theory courses have become online courses, it is difficult to make specific statistics for teachers' off-class tutoring regardless of workload. Teachers' workload is basically halved, from 4 hours per week to 2 hours per week. Shocked the teacher's enthusiasm for tutoring. These drawbacks are also reflected in the teaching effect. Table 2 is the statistics of teaching situation.

Table 2. Statistics of 020 teaching mode (the second half of 2019).

\begin{tabular}{llllll}
\hline Class & Final exam & Test & Attendance & Comprehensive & Failing \\
\hline ClassA & 67.9 & 73.2 & 98.0 & 72.0 & 1 \\
ClassB & 67.2 & 63.8 & 83.3 & 68.1 & 2 \\
ClassC & 69.3 & 78.9 & 84.6 & 72.8 & 1 \\
ClassD & 68.8 & 70.3 & 81.6 & 70.4 & 0 \\
average & 68.3 & 71.6 & 86.9 & 70.8 & \\
\hline
\end{tabular}

(Data source: Statistics of Li Zhanguo's teaching class).

In Table 2, the final exam results use the same test method as the traditional teaching method, but compared with the traditional method results, it can be seen that the average score is only 68.3 points, which is 8.3 points lower than the traditional method. We are shocked by this difference! But through analysis, we believe that this result is understandable. In the traditional teaching mode, theoretical teaching is that the teacher directly lectures to students in the classroom. Although some students may look at their mobile phones, most students still have good results. However, in the $\mathrm{O} 2 \mathrm{O}$ mode, due to the complete reliance on students' self-study in online courses, the content of their own online courses may affect the learning effect of students, and some students have the phenomenon of brushing courses, so the final grade is relatively low. In addition, the type and content of the test questions also have certain problems. We have improved this problem in the OL mode. The experimental platform and assessment method are exactly the same as the traditional teaching mode.

The total average score of the experiment is 71.6 points, and the biggest difference between classes is 14.2 points, and they are different classes of the same major. The main reason is the class management. Compared with the traditional teaching mode, the total average score of the experimental results is 15.4 points lower than that in the traditional mode. This difference is very large. The main reason is that the online courses are not enough for self-study and the necessary operating skills are not learned well. In addition, teachers need to strengthen guidance in the experimental courses.. In response to this problem, we have also made improvements in OL mode.

Online learning and attendance are the online learning time (obtained from the online teaching platform) and the comprehensive score of the attendance of each experimental class (the ratio is $2: 1$ ). This score is 12.9 points lower than the traditional teaching model, mainly due to the lack of learning time for online courses.

The comprehensive score is the score calculated according to the ratio of the previous scores, and the calculation method is the same as the traditional model. The total average score is 70.8 points, which is 10.3 points lower than the traditional model. The grade score can only reach the middle level, and the teaching model needs to be further improved.

In short, the $\mathrm{O} 2 \mathrm{O}$ teaching model has certain advantages compared with the traditional teaching model, such as the effective use of online teaching resources, and the ability to save offline teaching resources and teaching hours. However, the teaching effect is one level worse than traditional teaching and needs further improvement.

\section{OL Teaching Mode}

The network online teaching model uses the network as the teaching support environment to form a stable relationship between teachers and students and the structure of the activity process. The network teaching model highlights the important position and function of the network in the teaching activities of teachers and students. A well-structured online teaching model can not only give full play to the advantages of the network, but also can effectively improve the learning effect of students.

The OL teaching model evolves the experimental teaching in the original $\mathrm{O} 2 \mathrm{O}$ teaching model from the laboratory to the student's autonomous experiment at home, while the theoretical teaching still uses the online online teaching model of the $\mathrm{O} 2 \mathrm{O}$ teaching model. In this mode, students are mainly self-directed learning, teachers mainly realize online teaching and management through the network teaching platform, and the final assessment is also carried out through the network platform. Therefore, this mode is generally used when students cannot study in school.

In the first half of 2020, due to the development of the COVID-19 epidemic, students could not come to school to study, and the school decided to adopt an online teaching model. Online teaching uses the learning through network teaching platform, which provides complete teaching registration and sign-in management, teaching resources release learning and information exchange, release and correction of experimental documents and homework, final exams and various data statistics, etc. Meet the normal network teaching work. Other platforms can be used as auxiliary or backup teaching platforms according to needs. For example, using Xuexitong (Chaoxing) and QQ live broadcast methods for live teaching during lectures, using Xuexitong exam platform for exams in exams, and Dingding Group live broadcast for invigilating. Use Tencent meeting for defense, etc.

In the OL mode, the network teaching resources are basically the same as the $\mathrm{O} 2 \mathrm{O}$ mode, and they are also released to the learning through teaching platform, and the 
teaching resources are improved according to the needs of the OL teaching mode. Due to changes in the class mode and environment, schools and departments worry that students will have difficulty learning while studying at home. They have adjusted their teaching content and progress during the teaching process to meet the premise of teaching goals. Try to minimize the difficulty of teaching. Since the experimental environment is in the student's location rather than the laboratory, the content of the experiment also changes according to the experimental environment. For example, some students may only have mobile phones but no computers. Therefore, the experimental content should be simplified on the one hand, and different arrangements should be made according to different platforms. Experiment content.

The teaching process is 2 hours a week. Due to the poor self-study effect of students' online courses in the $\mathrm{O} 2 \mathrm{O}$ mode, and the poor experimental results, we modified the teaching method. Each course must first sign in before the class, and to achieve interaction during the course, so as to ensure that students will not have problems when they are not in class. In the online course study, according to the teaching content, every next class must be checked the progress of the online course of the previous class, so as to avoid the problem of students focusing on the lesson. In the homework, each class is assigned a network homework, which must be completed within a week. In the experiment, students choose the completed homework according to their own experimental environment and complete it within the specified time. Table 3 is the statistical results of the teaching situation (due to too many classes, only some of the class statistical results are selected).

Table 3. Statistics of OL teaching mode (first half of 2020).

\begin{tabular}{llllll}
\hline Class & Final exam & Test & Attendance & Comprehensive & Failing \\
\hline ClassA & 93.7 & 88.1 & 98.1 & 93.0 & 0 \\
ClassB & 93.0 & 82.7 & 100 & 91.6 & 0 \\
ClassC & 89.8 & 70.2 & 95.3 & 87.8 & 0 \\
ClassD & 91.3 & 71.8 & 95.6 & 88.3 & 1 \\
average & 92.0 & 78.2 & 97.3 & 89.8 & \\
\hline
\end{tabular}

(Data source: Statistics of Li Zhanguo's teaching class)

The OL teaching model mainly adopts the learning through platform and uses different indicators to evaluate the learning situation and final assessment of online courses. The final exam result is a case operation exam question using highly practical office software applications. This requires students to have good practical skills. Judging from the test results, the total average score is 92.0 points, which is higher than the traditional mode and $\mathrm{O} 2 \mathrm{O}$ mode. This situation is beyond our expectations. We think that in the home environment, the experimental conditions are not the school, the practical operation should be a weakness, but from the results, this assessment method is better than the theoretical assessment, and it is more suitable for the cultivation of students' hands-on ability.

The experiment score is a comprehensive score of the experiment report and homework, with an average score of 78.2. Although this score is 8.8 points lower than the traditional model, it is 6.6 points higher than the $\mathrm{O} 2 \mathrm{O}$ model. This score is still acceptable in the home experimental environment of independent learning.

Online score is the sum of online learning and course check-in scores, and the ratio between them is $2: 1$. The online learning score is the video learning score of the Xuexitong platform, which is the same as the $\mathrm{O} 2 \mathrm{O}$ model statistics. The check-in result is the check-in for each class, and is also the statistical result of the learning pass platform. The total average score of the two scores is 97.3 points, which shows that the assessment of curriculum teaching management and students' self-learning ability is very good, and there is no problem of poor network teaching management and insufficient self-learning ability that schools worry about.

The overall average score of the composite score is 89.8 points, which is much higher than the other two modes of 8.7 points and 19 points. This result shows that: 1) The online course sign-in has solved the teaching management problem and increased the class attendance rate; 2) Through the teacher's classroom experiment demonstration, the students' learning goals and practical skills have been enhanced, and the students' experimental results have been improved; 3) Through the change of the content of the final exam, the exam is closer to the cultivation of practical ability, and the final exam results have been improved.

\section{The Characteristics of the Three Teaching Modes}

Through the discussion of the three teaching modes, we can see that each teaching mode has its own characteristics. The specific advantages and disadvantages are summarized as follows.

\subsection{Advantages and Disadvantages of Traditional Teaching Mode}

The traditional teaching mode is based on classroom and laboratory teaching. Its characteristic is that the teacher takes the lead, and the students complete the learning tasks assigned by the teacher. The main advantage of this teaching mode is that the teacher has strong control over teaching activities and can complete the teaching tasks according to the teacher's teaching goals. However, this kind of teaching mode is too centralized management, which makes the students' learning initiative insufficient, and the utilization rate of online teaching resources is very low. This teaching mode has a lot to do with the teacher's teaching level in terms of teaching effect.

\subsection{Advantages and Disadvantages of O2O Teaching Mode}

The $\mathrm{O} 2 \mathrm{O}$ teaching mode is based on online teaching resources plus laboratory teaching. Its advantage is that it can make full use of Internet teaching resources and 
experimental teaching can be completed in the laboratory to ensure the level of experimental teaching. However, this teaching model is not easy to achieve centralized management in the management of online learning, and it is not easy to control the online learning process. Teaching effect has a great relationship with teaching process management.

\subsection{Advantages and Disadvantages of OL Teaching Mode}

The characteristic of the OL teaching mode is the complete use of Internet teaching and remote experimental teaching, which can realize remote teaching. Its biggest advantage is to realize decentralized teaching activities when the conditions are not available for centralized teaching in schools. However, in the teaching process, the quality of network teaching resources and the quality of teaching process management directly affect the teaching effect.

\section{Conclusion}

Through the discussion of the traditional teaching mode, O2O teaching mode and OL teaching mode, this paper makes a comprehensive evaluation of the three teaching modes by comparing and analyzing the results of teaching practice in three semesters. Each of these teaching modes has its own characteristics and is not a substitute for each other. Appropriate teaching modes should be selected according to different teaching conditions and teaching environments. As long as the teaching methods and teaching goals are adjusted according to the teaching environment, with the joint efforts of teachers and students, each teaching mode can achieve better teaching results and satisfy Achievement of teaching goals.

\section{Project Source}

Pingdingshan University Teaching Reform Project: Research on the Teaching Mode of University Computer Basic Courses Based on OBE in O2O Environment (No.: 2018-JY13).

\section{References}

[1] Yang Feng, Yin Defeng, Liu Ying, Wu Yang, Liu Jitao. Comparative study of PBL+EBM, MOOC combined teaching mode and traditional teaching mode. Southwest Military Medical, 2020, 22 (05): 493-495.

[2] Xie Haifen, Mou Haichuan, Xu Fei, Luo Dubin. The practice of teaching mode combining MOOC and traditional teaching in curriculum teaching. Education Teaching Forum, 2020 (35): 219-220.
[3] Ma Luyan, Zhang Xuexin. The characteristics of "teaching" in the bisection classroom teaching model. Heilongiiang Education (Theory and Practice), 2020 (10): 75-76.

[4] Li Mengduan, Zhang Linyu, Zhu Zhimin. A survey of the status quo of student identity cognition under the split-class teaching model-Taking College English as an example. Heilongjiang Education (Theory and Practice), 2020 (10): 72-74.

[5] Yang Yuling, Luo Lan, Qian Yuan, Yang Fang. Cultivation of the self-learning ability of medical genetics of undergraduates in separate classrooms. Heredity: 1-10 [2020-10-11]. http://kns.cnki.net/kcms/detail/11.1913.R.20200928.1107.002. html.

[6] Ma Sien. Research on online and offline hybrid teaching mode based on micro-classes. Education Teaching Forum, 2020 (43): 219-220.

[7] Yang Ruoyu, Jin Feng, Cai Ming. Exploration of online and offline teaching mode in the teaching reform of "Physiotherapy". Education Teaching Forum, 2020 (43): 204-205.

[8] Jin Miao, Gao Dongmei. Practical research based on online and offline hybrid teaching mode. Health Vocational Education, 2020, 38 (18): 86-87.

[9] Han Shuxia, Bi Zhiwei, etc. Teaching practice of calculus in large classes based on SPOC mixed teaching mode. Higher Education of Sciences. 2019 (01): 62-67+73.

[10] Li Wei. Comparative study of three common mixed teaching modes under the background of MOOC. Modern Educational Technology. 2018 (S1): 5-10.

[11] Bai Guang. Research on OBE engineering talent training mode under $\mathrm{O} 2 \mathrm{O}$ environment [D] Harbin University of Science and Technology. 2017, 06.

[12] Xu Buyi, Hu Yan. Curriculum resources and teaching model design for online teaching. Education Teaching Forum, 2020 (43): 202-203.

[13] Zhao Dan. Practice and effect analysis of online teaching. Education Teaching Forum, 2020 (43): 283-284.

[14] Tan Xuejie, Tian Yan, Xing Dianxiang, Hei Xiaoming. Reform and exploration of curriculum teaching mode under the background of "Internet +". Education Teaching Forum, 2020 (38): 201-202.

[15] Wang Nannan. Research on the mobile teaching mode based on the Chaoxing Learning Communication Platform-Taking the "Practical Law Basic Course" of TV University as an example. Education Teaching Forum, 2020 (40): 194-195.

[16] Li Ruwen. The transformation of teaching methods under the "cloud teaching" mode of colleges and universities-Taking Tianfu College of Southwestern University of Finance and Economics as an example. Science \& Technology Economic Guide, 2020, 28 (24): 154-155. 